\title{
The epidemiology of Huntington's disease in Northern Ireland
}

\author{
P J Morrison, W P Johnston, N C Nevin
}

\begin{abstract}
A survey of Huntington's disease (HD) in Northern Ireland, with a population of 1.5 million, has shown a 1991 prevalence rate of $6 \cdot 4 / 100000$. Virtually complete ascertainment was achieved, enabling prevalence rate estimates and age statistics to be calculated over the last 20 years. The prevalence rate is similar to the high prevalence rates of HD found in most European populations, suggesting the presence of either one extremely ancient or a number of separate mutational origins, resulting in a uniform European HD prevalence. The ages at diagnosis and duration of the disease are similar to previous studies, suggesting a consistent effect of the HD gene in all families. Estimates of heterozygote frequency (HF), direct and indirect mutation rate, fertility, and genetic fitness (W) were made. Reliable HF estimates gave values between 10 and $11 \times 10^{-5}$. The direct and indirect mutation rates were $0.32 \times 10^{-6}$ and $1.05 \times 10^{-6}$ respectively. $W$ was increased in the affected HD population but decreased in the at risk population. Fertility in HD is not reduced, but it appears that at risk patients have actively limited their family size. Factors responsible include, among others, the fear of developing HD and genetic counselling of families.
\end{abstract}

This is the first published epidemiological survey to include ascertainment data in a population both before and after isolation of the HD gene, and with the diagnosis in virtually all patients confirmed by DNA mutation testing.

( $\mathcal{f}$ Med Genet 1995;32:524-530)

Huntington's disease (HD) is an autosomal dominant neurogenetic movement disorder with cognitive and psychiatric dysfunction. ${ }^{1}$ The IT15 HD gene was isolated in March $1993^{2}$ and is a trinucleotide repeat. ${ }^{3}$ This has enabled simple confirmation of the diagnosis in virtually all cases of $\mathrm{HD} .{ }^{4}$ We have undertaken a large epidemiological study of HD in Northern Ireland, with the purpose of achieving virtually total case ascertainment. Direct DNA testing has enabled for the first time very accurate epidemiology statistics to be calculated for a complete population. Previous studies have used incomplete data or cases diagnosed on clinical examination and family history only.
This study includes all familial cases and also cases with no definite or substantiated family history, all confirmed as HD on genetic testing. Inclusion of all possible cases is important to obtain a true reflection of the population epidemiology.

There have been few studies on Huntington's disease in Northern Ireland (NI). Stevenson ${ }^{5}$ identified three families with HD referred from neurologists, and calculated a prevalence rate of 8 per million. Although the figure is a gross underestimate, it is similar to the historical estimate for south Wales. ${ }^{6}$

In 1975, a further survey was initiated. This survey, which was over two years, used multiple sources of ascertainment. The findings were presented at a symposium on HD in London in 1976 (N C Nevin, unpublished data). There were 93 affected patients in a population of 1.536 million, giving a prevalence rate of $6.05 \times 10^{-5}$. A review of the case records shows that some families did not have HD, and there was incomplete ascertainment. The survey was valuable in that it provided records on HD for the Department of Medical Genetics and alerted clinicians, including psychiatrists and neurologists, to the importance of genetic counselling for HD patients. The present survey was made easier, as these earlier records included full pedigrees and were an important source of ascertainment. No published prevalence rates for $H D$ are available from the Republic of Ireland, except for County Donegal, with a prevalence of 1.6 per 100000 , low because of exceptional emigration and family size patterns. ${ }^{7}$ HD in Great Britain has been studied more than in any other part of the world. Prevalence rates are available for more than 15 regions and over 20 reports $^{8-27}$ have been published (table 1). Prevalence rates vary considerably and the older the study, the greater the likelihood of incomplete ascertainment.

There is no obvious concentration of HD in the UK. Studies particularly mentioning Irish ancestry (not always clarified as NI or the Republic of Ireland) have been reported; several publications mention spread of HD from Ireland to the USA, ${ }^{28-30}$ to Canada, ${ }^{31}$ and to other areas of the United Kingdom, including Scotland ${ }^{23}$ and England. ${ }^{15} 19$ Several NI HD families have relatives in Canada, United States, Scotland, and the south-east of England.

\section{Population studied}

Northern Ireland consists of the six counties of modern Ulster. The total population recorded at the last census on 21 April 1991 was 
Table 1 Minimum prevalence figures for $H D$ per 100000 population in the British Isles

\begin{tabular}{lccc}
\hline Area & Reference & Year & Prevalence \\
\hline England & & & \\
Home Counties & 8 & 1934 & $0 \cdot 19-1 \cdot 25$ \\
London & 9 & 1938 & $1 \cdot 8$ \\
Cornwall & 10 & 1953 & $5 \cdot 57$ \\
Northamptonshire & 11 & 1954 & $4 \cdot 9$ \\
Northamptonshire & 12 & 1955 & $6 \cdot 0$ \\
Northamptonshire & 13 & 1960 & $7 \cdot 2$ \\
Northamptonshire & 14 & 1970 & $6 \cdot 3$ \\
N E London/Essex & 15 & 1967 & $2 \cdot 5$ \\
Bedfordshire & 16 & 1971 & $7 \cdot 5$ \\
Somerset & 17 & 1975 & $5 \cdot 5$ \\
Leeds/Yorkshire & 18 & 1976 & $4 \cdot 17$ \\
East Anglia & 19 & 1977 & $9 \cdot 24$ \\
$\begin{array}{l}\text { Scotland } \\
\text { Moray Firth }\end{array}$ & 20 & 1962 & $560 \cdot 0$ \\
South east Scotland & 21 & 1967 & $7 \cdot 2$ \\
West Scotland & 22 & 1970 & $5 \cdot 2$ \\
Edinburgh \& & & & \\
$\quad$ Lothian & 23 & 1970 & $6 \cdot 5$ \\
Grampian & 24 & 1989 & $9 \cdot 94$ \\
Wales & & & \\
South Wales & 25 & 1979 & $7 \cdot 5$ \\
South Wales & 26 & 1981 & $7 \cdot 61$ \\
South Wales & 27 & 1988 & $8 \cdot 5$ \\
North Wales & 27 & 1988 & $5 \cdot 5$ \\
Ireland & & & \\
County Donegal & 7 & 1991 & $1 \cdot 6$ \\
Northern Ireland & Present study & 1991 & $6 \cdot 4$ \\
\hline
\end{tabular}

1569971 (764818 males, 805153 females). At the 1981 census, the population was 1532196 . Over the last 40 years, the population has remained static with a small nett loss owing to emigration, with minimal immigration. This feature has been useful in estimating the accurate prevalence of some genetic diseases. ${ }^{32}$ The gene pool in NI, unlike some other European countries, was firmly laid down in the early 13th century and has remained reasonably constant. ${ }^{3334}$

\section{Methods}

Index cases with HD were ascertained from multiple sources. All general practitioners, adult and paediatric neurologists, psychiatrists, and geriatricians were asked to supply names and addresses of known patients. The death registers of psychiatric hospitals, and diagnostic indices of major teaching hospitals, were also sources of ascertainment. The diagnostic records in the Department of Medical Genetics from 1967 provided details of several HD families, and included records from the 1976 survey which was not completed. A very intensive search for secondary cases was made with multiple family members being approached and examined or counselled.

The HD patients were clinically examined and a detailed history of the symptoms and progress of the disease was obtained from either the patient or from a reliable relative. The information was validated by psychiatric, neurological, and genetic case notes. Blood $(20 \mathrm{ml})$ was collected from each patient in an EDTA tube. Detailed pedigrees were obtained for each family. In a small number of families, reference to family bibles and church records were also of value in establishing links between families. Dates of birth, death, and duration of illness were noted for all affected members.

Initially, inclusion criteria for the diagnosis of HD included the presence of chorea, de- mentia, or psychiatric disturbance in a patient with progressive course and with a family history of similar illness. Atypical patients were included if there was a family history of the disease in a typical form. Typical patients with a negative family history were also included. One family with a previous diagnosis of benign chorea $^{35}$ was included after revision of the diagnosis. ${ }^{3637}$ Confirmation of the diagnosis of HD on DNA testing has now been made in all of the 101 living patients ascertained (manuscript in preparation).

\section{PREVALENCE RATE}

In the calculation of the prevalence rate, two dates were chosen, the first the April 1981 census, and the second the 21 April 1991 census. The first provided a more complete identification of patients who had been diagnosed or had died before 1991. The second was chosen to eliminate problems based on possible inaccurate information on older patients. The prevalence rate on 1 April 1971 was also calculated, and the rate of the 1976 survey was revised.

\section{AGE AT ONSET}

Information was obtained from multiple sources including the patient and from one or more close relatives. The patient's assessment was disregarded if the relative's assessment differed. Onset was defined as the age at which progressive neurological or psychiatric symptoms first appeared. Neurological symptoms were almost always choreiform movements. Psychiatric symptoms included signs of dementia or other overt psychiatric symptoms.

\section{AGE AT DIAGNOSIS}

This information was recorded from hospital case notes and has been taken as either when the first definite diagnosis was made or when the diagnosis of HD was strongly suspected.

\section{AGE AT DEATH}

In almost all cases the age at death was recorded in hospital case records or was clearly available from relatives. In many instances this date was confirmed by a death certificate.

\section{HETEROZYGOTE FREQUENCY AND MUTATION}

RATE

The heterozygote frequency was estimated using four methods based on Stevens's classification. ${ }^{18}$ Method 1 consists of simple summation of all patients (with $50 \%$ risk, $25 \%$ risk, $12.5 \%$ risk, and so on) at risk of inheriting the HD gene. This total is then divided by the population. ${ }^{28}$ Method 2 was previously described by Cameron and Venters, ${ }^{21}$ and method 4 by Reed and Chandler. ${ }^{28}$ Method 3 involves regression analysis of parent-child pairs and using the results to construct a risk curve. The results can then be used in method 2 to produce a more accurate figure. The gene frequency in 


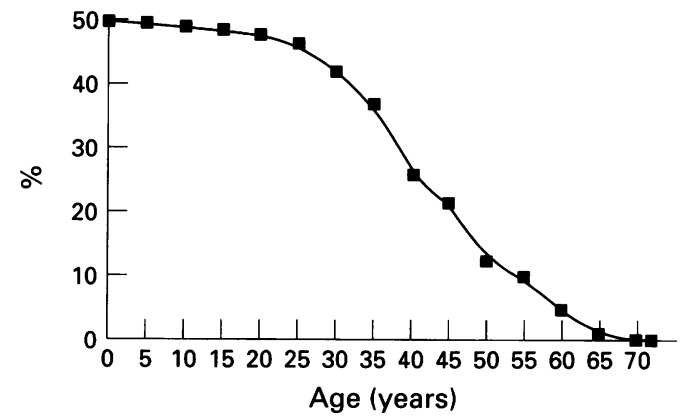

Figure 1 Risk of an unaffected subject at $50 \%$ prior risk for $H D$ carrying the HD gene at a particular age.

Table 2 The modes of ascertainment of people affected and at risk for HD in Northern Ireland. Equivocal cases are excluded

\begin{tabular}{lcrr}
\hline Source & Affected & At risk & Total \\
\hline Neurologist & 2 & 0 & 2 \\
General practitioner & 3 & 27 & 30 \\
Family tracing & 12 & 95 & 107 \\
Other clinicians & 0 & 0 & 0 \\
Existing pedigrees & 84 & 964 & 1048 \\
Total & 101 & 1086 & 1187 \\
\hline
\end{tabular}

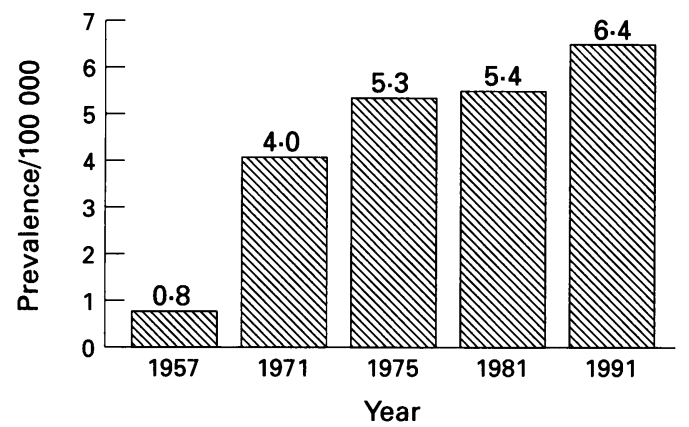

Underestimates likely for 1957 and 1971

Figure 2 Prevalence of $H D$ in Northern Ireland.

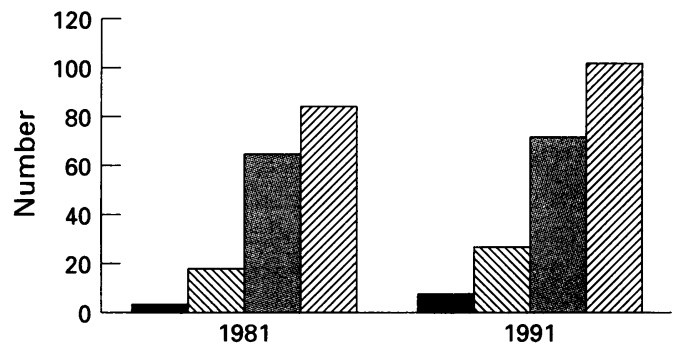

\begin{tabular}{ll|}
\hline Juvenile <20 & Late onset $>50$ \\
Standard & एatal
\end{tabular}

Figure 3 Category of HD in the 1981 and 1991 cohorts.

all cases is half of the heterozygote frequency. In each case, data refer to a 1991 prevalence rate. ${ }^{36}$ All heterozygote frequency measurements are indirect; true data require molecular analysis of a complete population. Using method $2,{ }^{18}$ age at onset data were used to construct cumulative percentage graphs of subjects who had become affected at various ages. The risk at age $\mathrm{X}(\mathbf{R x})$ was calculated, and a graph derived from these figures was constructed showing the values of the risk at age $\mathrm{X}$ for different ages. The risk to a person of the given age can then be read directly from the graph (fig 1).

The direct and indirect mutation rates were also calculated. ${ }^{1838}$

FERTILITY AND GENETIC FITNESS

Fertility is the number of live births to a person. ${ }^{182938}$ This was calculated for the living affected cohort and the living at risk cohort (B1), and the normal population cohort (B2). Population data corrected for age and sex were provided by the Registrar General for Northern Ireland. These data were used to calculate fitness (W) rather than family or spouse controls which are subject to bias. ${ }^{39-41}$

\section{Results}

Seventy-four kindreds were identified, with all affected people resident in NI. The modes of ascertainment are shown in table 2. Most patients were already known to the Genetics Centre, and of the referrals not known three were ascertained through general practitioners (GPs). Two patients ascertained from neurological referrals of patients with features similar to HD but no definite family history were shown to have HD on DNA testing. No new patients were ascertained through general physicians, geriatricians, or psychiatrists and eight patients were ascertained by tracing of families already known to the Genetics Centre. All of these patients, except one referred by a GP, were alive on prevalence day. There were definite replies from 510/900 GPs. The exact number of nil returns is not known, as some GPs appeared to reply on behalf of their practice partners but the complete return rate is estimated as between $60 \%$ and $70 \%$.

A total of 101 affected subjects was alive on the 1991 prevalence day; 441 relatives at $50 \%$ risk, 591 relatives at $25 \%$ risk, and 54 people at $12.5 \%$ or less risk were alive, making a total of 1086 at risk relatives. The number of $12.5 \%$ or less at risk relatives is small, as expected, as several of the $25 \%$ risk group are only now reaching childbearing age. The prevalence for years $1971,1975,1981$, and 1991 is shown in fig 2 . The 1991 figure is the minimum prevalence rate for the living affected cohort with a rate of 6.4 per 100000 . In 1981 there was a total of 83 affected of whom 38 were male and 45 were female. In 1991 there were 101 affected, of whom 49 were male and 52 were female. The type of onset of HD is shown in fig 3. Of the living cohort, $7 \%$ had juvenile onset HD (onset less than 20 years) and, of these, $3 \%$ were very early (childhood) onset HD of less than 10 years. Twenty-five percent had late onset HD, over 50 years. For the 1981 cohort, $16 \%$ had late onset $\mathrm{HD}$ and $4 \%$ had juvenile onset HD. The range of age of onset for the living cohort was 3 to 72 years. The mean and standard deviation of age at onset, age at diagnosis, age at death, and duration of symptoms in 143 patients born between 1920 
Table 3 Age statistics for the 1920-1991 cohort

\begin{tabular}{lllll}
\hline & Onset & Diagnosis & Death & Duration \\
\hline Years & 43.6 & $44 \cdot 7$ & $56 \cdot 2$ & $16 \cdot 4$ \\
SD & 13.5 & 13.3 & 13.3 & $5 \cdot 8$ \\
\hline
\end{tabular}
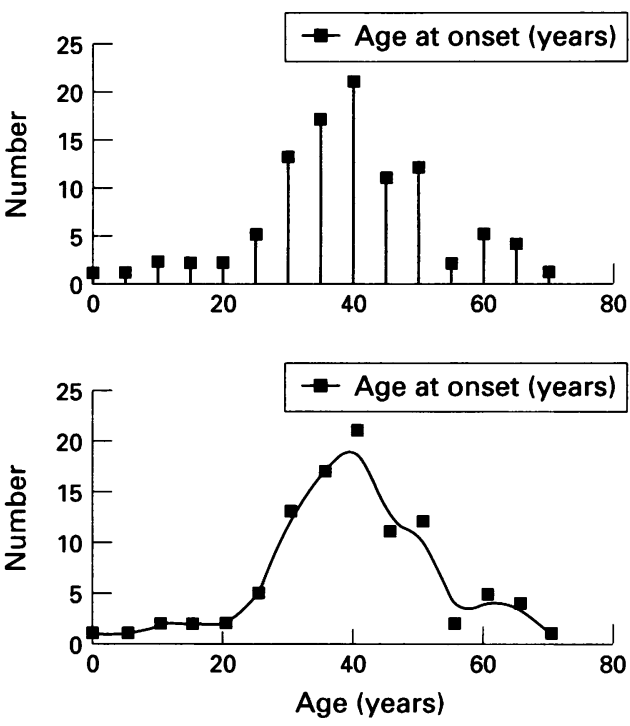

Figure 4 Age at onset plot and curve for the 1991 living cohort.
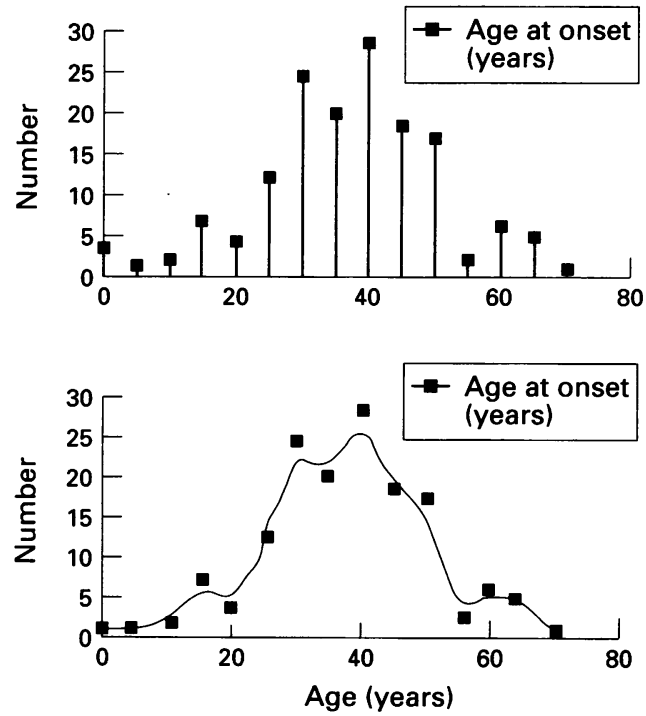

Figure 5 Age at onset plot and curve for the 1920-1991 cohort.

and 1991 is shown in table 3. The average age of onset in the living cohort was $40 \cdot 87$ years and average age at diagnosis was $44 \cdot 4$ years (fig 4). The average age of onset in the 1981 cohort was 39.6 years with an age at diagnosis of 44.6 years (fig 5). Tables 4 and 5 record the frequency distributions of age at onset for the 1991 living cohort and a cohort born between 1920 and 1991. Heterozygote frequencies are shown in table 6 with comparison with the survey from south Wales. ${ }^{26}$ The risk of an unaffected subject at $50 \%$ prior risk for HD carrying the HD gene is shown in fig 1 . Direct and indirect mutation rates are shown in table
Table 4 Frequency distribution of the age at onset of $H D$ in the living cohort 1991

\begin{tabular}{cccr}
\hline Age & No at each age & Cumulative total & $\%$ \\
\hline $0-4$ & 1 & 1 & 1 \\
$5-9$ & 1 & 2 & 2 \\
$10-14$ & 2 & 4 & 4 \\
$15-19$ & 2 & 6 & 6 \\
$20-24$ & 2 & 13 & 9 \\
$25-29$ & 5 & 26 & 14 \\
$30-34$ & 13 & 45 & 28 \\
$35-39$ & 19 & 66 & 44 \\
$40-44$ & 21 & 89 & 65 \\
$45-49$ & 11 & 91 & 76 \\
$50-54$ & 12 & 96 & 88 \\
$55-59$ & 2 & 100 & 90 \\
$60-64$ & 5 & 101 & 95 \\
$65-69$ & 4 & & 99 \\
$70+$ & 1 & & 100 \\
\hline
\end{tabular}

Table 5 Frequency distribution of the age at onset of $H D$ in the 1920-1991 cohor

\begin{tabular}{lccr}
\hline Age & No at each age & Cumulative total & $\%$ \\
\hline $0-4$ & 1 & 1 & 1 \\
$5-9$ & 1 & 2 & 2 \\
$10-14$ & 2 & 4 & 4 \\
$15-19$ & 7 & 11 & 6 \\
$20-24$ & 4 & 27 & 9 \\
$25-29$ & 12 & 51 & 14 \\
$30-34$ & 24 & 71 & 28 \\
$35-39$ & 20 & 99 & 44 \\
$40-44$ & 28 & 113 & 65 \\
$45-49$ & 14 & 130 & 73 \\
$50-54$ & 17 & 139 & 86 \\
$55-59$ & 2 & 132 & 89 \\
$60-64$ & 6 & 138 & 95 \\
$65-69$ & 5 & 144 & 99 \\
$70+$ & 1 & & 100
\end{tabular}

Table 6 Heterozygote frequency in the HD population

\begin{tabular}{lll}
\hline Method & Frequency & Comparison \\
\hline 1 & $15 \cdot 50$ & 34.9 \\
2 & $6 \cdot 34$ & $17 \cdot 2$ \\
3 & $10 \cdot 94$ & 25 \\
4 & 11.03 & 17 \\
\hline
\end{tabular}

7. Distribution of family size is shown in tables 8 and 9 for the living affected and at risk cohorts. The fertility and genetic fitness (W) of the two groups is shown in tables 10 and 11. Comparisons of $W$ for the affected (c), at risk $(n)$, and control $(\mathrm{p})$ populations are shown in table 12 .

\section{Discussion}

A variety of methods of ascertainment have been used and it is considered that virtually all affected people have been identified. Within the last three years, only one single case from a new family and one single case from an already known family have been identified. Both cases had onset of symptoms after 1991. The geographical size of NI is well suited to population surveys. However, even with the multiple methods of ascertainment, only 17 new affected patients have been discovered during the time of the survey (table 2). Of the 17 patients, 12 were secondary cases, ascertained from known HD families. Most cases had multiple ascertainment sources. Some families or some branches of families with no currently living affected members could still produce an affected subject either because of denial by the 
Table 7 Mutation rates in the HD population

$\begin{array}{ll}\text { Direct } & 0.32 \times 10^{-6} \\ \text { Indirect } & 1.05 \times 10^{-6}\end{array}$

Indirect $1.05 \times 10^{-6}$ Table 8 Distribution
subjects alive in 1991

\begin{tabular}{|c|c|c|c|c|c|c|c|c|c|}
\hline \multirow{2}{*}{$\begin{array}{l}\text { No of } \\
\text { live births }\end{array}$} & \multicolumn{3}{|c|}{ Males } & \multicolumn{3}{|c|}{ Females } & \multicolumn{3}{|c|}{ Total } \\
\hline & $S$ & $M$ & $T$ & $S$ & $M$ & $T$ & $S$ & $M$ & $T$ \\
\hline $\begin{array}{c}0 \\
1 \\
2 \\
3 \\
4 \\
5 \\
6 \\
7 \\
8 \\
9 \\
10+\end{array}$ & 11 & $\begin{array}{r}1 \\
4 \\
12 \\
2 \\
5 \\
1 \\
1 \\
2 \\
1\end{array}$ & $\begin{array}{r}12 \\
4 \\
12 \\
2 \\
5 \\
1 \\
1 \\
2 \\
1\end{array}$ & 3 & $\begin{array}{r}6 \\
5 \\
5 \\
14 \\
8 \\
2 \\
3 \\
2 \\
1 \\
1\end{array}$ & $\begin{array}{r}9 \\
5 \\
5 \\
14 \\
8 \\
2 \\
3 \\
2 \\
1 \\
1\end{array}$ & 14 & $\begin{array}{r}7 \\
9 \\
17 \\
16 \\
13 \\
3 \\
4 \\
2 \\
3 \\
1 \\
1\end{array}$ & $\begin{array}{r}21 \\
9 \\
17 \\
16 \\
13 \\
3 \\
4 \\
2 \\
3 \\
1 \\
1\end{array}$ \\
\hline
\end{tabular}

$\mathrm{S}=$ single, $\mathrm{M}=$ married, $\mathrm{T}=$ total.

Table 9 Distribution of family size in at risk (Wn) subjects alive in 1991

\begin{tabular}{|c|c|c|c|c|c|c|c|c|c|}
\hline \multirow{2}{*}{$\begin{array}{l}\text { No of } \\
\text { live births }\end{array}$} & \multicolumn{3}{|c|}{ Males } & \multicolumn{3}{|c|}{ Females } & \multicolumn{3}{|c|}{ Total } \\
\hline & $S$ & $M$ & $T$ & $S$ & $M$ & $T$ & $S$ & $M$ & $T$ \\
\hline $\begin{array}{c}0 \\
1 \\
2 \\
3 \\
4 \\
5 \\
6 \\
7 \\
8 \\
9 \\
10+\end{array}$ & 8 & $\begin{array}{r}4 \\
9 \\
13 \\
7 \\
7 \\
4 \\
3\end{array}$ & $\begin{array}{r}12 \\
9 \\
13 \\
7 \\
7 \\
4 \\
3\end{array}$ & 6 & $\begin{array}{r}8 \\
8 \\
14 \\
11 \\
7 \\
3 \\
1 \\
1\end{array}$ & $\begin{array}{r}14 \\
8 \\
14 \\
11 \\
7 \\
3 \\
1 \\
1\end{array}$ & 14 & $\begin{array}{r}12 \\
17 \\
27 \\
18 \\
14 \\
7 \\
4 \\
1\end{array}$ & $\begin{array}{r}26 \\
17 \\
27 \\
18 \\
14 \\
7 \\
4 \\
1\end{array}$ \\
\hline
\end{tabular}

$\mathrm{S}=$ single, $\mathrm{M}=$ married, $\mathrm{T}=$ total.

The population fertility $(\mathrm{Wp})=2 \cdot 24$

Table $10 B_{1}$ values for the affected (c) and at risk (n) populations

\begin{tabular}{lrlr}
\hline \multicolumn{1}{c}{ Male } & Female & \multicolumn{1}{l}{ Total } \\
\hline (c) & $92 / 40=2 \cdot 3$ & $148 / 50=2 \cdot 96$ & $240 / 90=2 \cdot 67$ \\
(n) & $122 / 55=2 \cdot 2$ & $125 / 59=2 \cdot 1$ & $247 / 114=2 \cdot 17$ \\
\hline
\end{tabular}

Table 11 Values of $W$ for male and female affected (c) and at risk $(n)$ populations

\begin{tabular}{lll}
\hline & $(c)$ & $(n)$ \\
\hline Male & $2 \cdot 30 / 2 \cdot 24=1 \cdot 03$ & $2 \cdot 22 / 2 \cdot 24=0 \cdot 98$ \\
Female & $2 \cdot 96 / 2 \cdot 24=1 \cdot 32$ & $2 \cdot 12 / 2 \cdot 24=0.93$ \\
\hline
\end{tabular}

family or lack of recognition of early $\mathrm{HD}$, although the numbers suspected should be minimal. Undoubtedly the number of cases ascertained has been facilitated by the earlier survey carried out in 1976. A number of smaller family groups have been successfully linked together to form larger families and some families have been linked on a more tentative basis. The 100 original families recorded in 1976 have been reduced to 74 by the exclusion of eight, in whom the diagnosis was revised, and by the addition of new families or amalgamation of pedigrees. Despite extensive genetic tracing, however, over 70 families remain unlinked; some are five or six generation families. This suggests evidence for more than one HD mutation origin. ${ }^{42}$ A small founder effect by having two or three large families in NI increases the prevalence more selectively in some regions. None of the families is large enough to cause bias in the population statistics, such as has occurred in the Tasmanian pedigree analysis ${ }^{43}$ or in areas of concentration of HD such as the Moray Firth. ${ }^{20}$

Four direct estimates of prevalence were made (fig 2). The three more recent estimates, 1975,1981 , and 1991, are considered to be very accurate. The 1971 estimate is a definite underascertainment and the fifth estimate in 1957 is included only out of historical interest. Different estimates were made to avoid the problem of setting a single prevalence date, which, if too remote, will lose early onset cases and, if too recent, will lose some late onset cases. It is felt that because of the extensive secondary family tracing, the 1991 prevalence date is not too recent. The prevalence rates are important because they show that the most westerly part of Europe has a prevalence rate virtually identical to the middle and east of Europe. Numerous studies within the United Kingdom offer more detailed analyses. ${ }^{1}$ Again the prevalence remains uniform between 5 and 10 per 100000 with no obvious prevalence gradient present. This suggests that a small number of separate mutational origins, some possibly very ancient, could account for the uniform prevalence of HD cases throughout Europe.

The age at onset tables and curves for both cohorts are very similar, suggesting reliable case ascertainment. The overall mean age of onset is 40.87 years, with no significant difference between males and females. An attempt was made when taking family histories to note any affected child with developmental delay or neurological symptoms in order to ascertain all juvenile $\mathrm{HD}$ cases, resulting in virtually total ascertainment. The mean age of onset is comparable to other recent surveys. ${ }^{26}$ It is unusual for patients to alter suddenly from a normal to an affected state, ${ }^{44}$ as a zone of onset rather than a fixed onset point occurs.

The age of diagnosis of the 1991 cohort and the 1981 cohort was 44.4 years and 44.6 years respectively. Over a 10 year period the interval between onset and diagnosis has decreased from 5 years to 3.5 years. Most earlier surveys show a lag of about 10 years between onset and diagnosis. Virtually all of the surveys were published before the onset of predictive testing. If the surveys were to be repeated now (with ascertainment and follow up of families following predictive testing and mutation analysis), the age should have fallen. Another reason for the smaller diagnosis interval in Northern Ireland is the excellent coordination of neurology, psychiatry, and genetics services. Families who have tentative diagnoses made in one specialty are promptly referred for genetic confirmation of the diagnosis. It is likely that the diagnostic interval will decrease further with predictive testing and direct mutation analysis, allowing follow up of several presymptomatic gene carriers.

The average age at death of patients who died between 1920 and 1991 is $56 \cdot 2$ years. This is remarkably similar to the ages at death of all reported major series on $\mathrm{HD}^{1}$ in which the range of age at death varies between 51 and 57 years. A future increase is likely, owing to improved diagnosis of previously unrecorded 
late onset cases and improvement in care of patients with HD. The duration of disease for the $1920-1991$ cohort is 13.4 years. There is no significant difference between males and females.

Two patients had no definite history of Huntington's disease and had atypical clinical features (tongue dystonia with minimal chorea in one patient, schizophrenia in another patient), and were ascertained only on analysis of DNA from 15 patients with an atypical phenotype and no obvious family history.

The number of accurate ascertainment surveys which have calculated the heterozygote frequency is small, because of the complex methods of analysis needed. The figure derived is important as it indicates the number of people in a community who are likely to develop the disease. Of the methods used, method 1 gives a theoretical risk based on the maximum number of at risk patients, and is usually approximately twice the true frequency in most surveys. ${ }^{2838}$ Method 4 gives an estimate within $10 \%$ of the true figure, ${ }^{28}$ and method 3 is the most accurate.$^{18}$ Accurate estimates give a value of $2.5 \times$ the prevalence estimate which, in the case of Northern Ireland, should give a value of between 15 and 18. Using methods 3 and 4 , the actual value is 11 , a figure of just under twice the prevalence. This low figure suggests that despite very good ascertainment of affected HD cases, there are fewer heterozygotes in the Northern Ireland population. Previous population studies have not achieved full ascertainment, and an estimate of $2.5 \times$ the population prevalence for this method is an overestimate. The low Northern Ireland figure is partly explained by the estimates of fertility and genetic fitness. Unlike other parts of Ireland, emigration is not a major cause. ${ }^{7}$ It has been shown that the total value of fertility for the living at risk cohort is $2 \cdot 17$ compared with the normal value of $2 \cdot 24$. The reproductive fitness value for the at risk group is 0.97 . These figures show that the family size of at risk patients has been limited more than that of the average population, thus reducing the number of heterozygotes that would be at risk. If factors, such as small family size of some affected patients owing to not having children voluntarily and, in some cases, because of sterilisation of the affected spouse, are considered, the natural fertility of the affected cohort without genetic and other counselling may have been higher. The direct mutation rate calculated is totally inaccurate as it is virtually impossible to identify true mutations in the population owing to lack of available DNA from parents or sibs. Fig 1 shows the curve for heterozygosity based on the age at onset data. The graph is almost identical to the study by Harper et $a l^{45}$ in Wales, confirming that there is little difference in heterozygote risk data between large $H D$ populations. It also underlines the importance of realising that several patients still have a high risk of developing symptoms of HD in their sixties. Individual risks can be calculated from published tables. ${ }^{45}$ Refinement of these tables should be possible with improved diagnosis with DNA markers and follow up of presymptomatic carriers giving more accurate age at diagnosis and onset. Some additional risk alteration to such tables may be possible in the future by incorporating both trinucleotide length and polymorphism data, ${ }^{46}$ and the sex of the affected parent.

The indirect mutation rate calculated using values of genetic fitness gives a value of $1.045 \times 10^{-6}$. This figure is much more reliable than the direct estimate and shows a minimum mutation rate which is one of the lowest human disease mutation rates currently known. No samples were identified in the control population with repeat sizes larger than 30 , although one at risk patient had repeat sizes of 33 and 44; therefore, no premutation patients with so called "intermediate alleles" 47 were identified.

It is certain that new mutation patients do exist in the population. Goldberg et $a l^{47}$ have calculated a mutation rate of $3 \%$ from an analysis of DNA samples in an incomplete ascertainment of patients. Our own indirect mutation rate is $1.7 \%$ of the population. As new mutation cases often present with later onset and smaller repeat size, some cases may not yet have been ascertained. A new mutation rate of the order of 2 to $3 \%$ is realistic for HD. The likelihood of obtaining DNA from "normal" parents to confirm or exclude paternity and repeat sizes is small in such cases, and makes diagnostic confirmation difficult.

Of the studies that have calculated fertility and genetic fitness in Huntington's disease, a third show a decrease in fertility and fitness, a third show values close to normal levels, and a third show an increase. ${ }^{1}$ The two main studies in the UK ${ }^{1839}$ both show an apparent increase in fertility and fitness. It would appear that within reliable studies, there is a static or slight but real increase in fertility and fitness. The reasons for this are unclear. In the Northern Ireland survey there is a significant increase in fertility and fitness when the affected cohort is compared to the at risk cohort. The difference is less marked when compared to the control population group. This reflects the heterozygote frequency figure which is lower than in most surveys. Most genetic diseases with an increased fitness imply selective biological advantage. It is unlikely that this is the case in $\mathrm{HD}$, although an increase in $\mathrm{HD}$ owing to mutational bias has been suggested. ${ }^{48} \mathrm{An}$ apparent lower incidence of cancers, even when corrected for age, has also been shown. ${ }^{49}$ It is more likely that because the gene affects primarily the brain, the subject's ability to plan a family successfully is in some way inhibited. This is borne out by comparison of the female affected and at risk fertility figures which are much higher than average in the case of affected females and lower in at risk females compared to at risk males. It is possible that a small number of children of affected fathers may be lost to the study because of non-paternity, but $48 \%$ of the affected HD patients were male, and this is consistent with the relative lower male fertility rate. Other studies have shown varying results ${ }^{50}$ and no consistency has been found.

Earlier diagnosis and presymptomatic 
screening of at risk relatives, with the prospect of treatment for $\mathrm{HD}$, will alter fertility and fitness over the coming decades, as reproductive choices can be made before having children, rather than after the family is virtually completed. Further epidemiology and natural history studies should yield clues to the reasons for varied fertility and fitness in $\mathrm{HD}$, and a more accurate mutation rate.

In summary, this study, with virtually complete ascertainment and confirmation of HD cases by DNA testing, shows a uniform European HD prevalence, with similar ages of onset, diagnosis, duration, and death to values found in the rest of the world. This suggests that the single IT15 mutation is consistent in its effect, and little clinical variation is caused by the environment or other external factors. New mutations must occur, and are more common than previously thought. Fitness, though difficult to measure accurately, appears to be slightly increased in HD.

PJM is in receipt of a Royal College of Physicians of Ireland Glaxo neurogenetics fellowship.

1 Harper PS, ed. Huntington's disease. London: W B Saunders, 1991.

2 The Huntington's Disease Collaborative Research Group A novel gene containing a trinucleotide repeat that is A novel gene containing a trinucleotide repeat that is expanded and unstable on Hunt

3 Morrison PJ. Trinucleotide repeat repeat repeat. Lancet 1993;342:385-6.

4 Kremer B, Goldberg P, Andrew SE, et al. A worldwide survey of the Huntington's disease mutation - the sensitivity and specificity of measuring CAG repeats. N Engl F Med 1994 330:1401-6.

5 Stevenson AC. Congenital abnormalities in Northern Ireland. Department of Social Medicine: The Queen's University of Belfast, 1957.

6 Spillane J, Philips R. Huntington's chorea in South Wales. $Q \mathcal{F}$ Med 1937;6:403-23.

7 Morrison PJ, Nevin NC. Huntington disease in County Donegal: epidemiological trends over four decades. Ulster Med f 1993;62:141-4.

8 Critchley M. Huntington's chorea and East Anglia. $\mathcal{F}$ State Med 1934;42:575-87.

9 Minski L, Guttman E. Huntington's chorea: a study of 34 families. $\mathcal{J}$ Ment Sci 1938;84:21-96.

10 Bickford JAR, Ellison RM. High incidence of Huntington's chorea in the Duchy of Cornwall. $\mathcal{f}$ Ment Sci 1953;99: $291-4$.

11 Pleydell MJ. Huntington's chorea in Northamptonshire. $B M F$ 1954;i:1121-8.

12 Pleydell MJ. Huntington's chorea in Northamptonshire. BMF 1955;ii:889.

13 Reid JJ. Huntington's chorea in Northamptonshire. BMF 1960;ii: 650 .

14 Oliver JE. Huntington's chorea in Northamptonshire. $\mathrm{Br} \mathcal{F}$ Psychiatry 1970;116:241-53.

15 Heathfield KWG. Huntington's chorea: investigation into the prevalence of disease in the area covered by the North East metropolitan board. Brain 1976;90:203-32.

16 Heathfield KWG, Mackenzie ICK. Huntington's chorea in Bedfordshire. Guy's Hosp Rep 1971;120:295-309.

17 Glendenning N. A study on Huntington's chorea. MD thesis, University of London, 1975.

18 Stevens DL. Huntington's chorea. A demographic, genetic and clinical study. MD thesis, University of London, 1976.

19 Caro AJ. The prevalence of Huntington's chorea in an area of East Anglia. $\mathcal{~} R$ Coll Gen Pract 1977;27:41-5.
20 Lyon RL. Huntington's chorea in the Moray Firth area BMF 1962;i:1301-6.

21 Cameron D, Venters GA. Some problems in Huntington' chorea. Scott Med f 1967;12:152-6.

22 Bolt JM. Huntington's chorea in the West of Scotland. B f Psychiatry 1970;116:259-70.

23 Venters G. Epidemiology of Huntington's chorea. $\mathrm{PhD}$ Thesis University of Edinburgh, 1971.

24 Simpson SA, Johnston AW. The prevalence and patterns of Huntington's chorea in Grampian. Br f Psychiatry 1989, 155:799-804.

25 Harper PS, Walker DA, Tyler A, Newcombe RG, Davies K Huntington's chorea. The basis for long term prevention. Lancet 1979;ii:346-9.

26 Walker DA, Harper PS, Wells CEC, et al. Huntington's chorea in South Wales. Clin Genet 1981;19:213-21.

27 Quarrell OWJ, Tyler A, Jones MP, Nordin M, Harper PS. Population studies of Huntington's disease in Wales. Clin Genet 1988;33:189-95.

28 Reed TE, Chandler JH. Huntington's chorea in Michigan. 1. Demography and genetics. Am $\mathcal{f}$ Hum Genet 1958;10: 201-25.

29 Reed TE, Neel JV. Huntington's chorea in Michigan. 2. Selection and mutation. Am $\mathcal{F}$ Hum Genet 1959;11:107-36. 30 Stone T, Falstein EI. Genealogical studies in Huntington's chorea. F Nerv Ment Dis 1939;89:795-809.

31 Barbeau A, Fulham G. Origin and migration of Huntington' chorea in Canada. Can Med Assoc $\mathcal{F}$ 1962;87:1242-3.

32 Stevenson AC. The load of hereditary defects in human populations. Radiat Res (Suppl) 1959;1:306-25.

33 Edwards RD. An atlas of Irish history. 2nd ed. London Routledge, 1981.

34 Bardon J. A history of Ulster. London: Blackstaff Press, 1992.

35 Quarrell OWJ, Youngman S, Sarfarazi M, Harper PS. Absence of close linkage between benign hereditary chorea and the

36 Morrison PJ. The epidemiology and genetics of Huntington's disease. MD thesis, The Queen's University of Belfast, 1993.

37 MacMillan JC, Morrison PJ, Nevin NC, et al. Identification of an expanded CAG repeat in the Huntington's disease of an expanded CAG repeat in the Huntington's disease gene (IT15) in a family reported to have
chorea. $\mathcal{F}$ Med Genet 1993;30:1012-13.

38 Conneally PM. Huntington's disease: genetics and epidemiology. Am $\mathcal{f}$ Hum Genet 1984;36:506-26.

39 Walker DA, Harper PS, Newcombe RG, Davies K. Hun tington's chorea in South Wales: mutation, fertility and genetic fitness. $\mathcal{F}$ Med Genet 1983;20:12-17.

40 Shaw M, Caro A. The mutation rate to Huntington's chorea. f Med Genet 1982;19:161-7.

41 Bundey S. New mutations in Huntington's chorea. $7 \mathrm{Med}$ Genet 1983;20:76-7.

42 Morrison PJ, Graham CA, Nevin NC. Significant linkage disequilibrium between the Huntington's disease locus and markers at D4S10, D4S95 and D4S111 in Northern Ireland. F Med Genet 1993;30:1018-19.

43 Pridmore SA. The prevalence of Huntington's disease in Tasmania. Med f Aust 1990;153:133-4.

44 Penney JB, Young AB, Shoulson I, et al. Huntington's disease in Venezuela: 7 years of follow-up on symptomatic and asymptomatic individuals. Movement Dis 1990;5:939.

45 Harper PS, Newcombe RG. Age at onset and life table risks in genetic counselling for Huntington's disease. $7 \mathrm{Med}$ Genet 1992;29:239-42.

46 Almqvist E, Spence N, Nichol K, et al. Ancestral differences in the distribution of the $\Delta 2642$ glutamic acid polymorphism is associated with varying CAG repeat lengths on normal chromosomes: insights into the genetic evolution of Huntington disease. Hum Mol Genet 1995;4 207-14.

47 Goldberg YP, Kremer B, Andrew SE, et al. Molecula analysis of new mutations for Huntington's disease: intermediate alleles and sex of origin effects. Nature Genet 1993;5:174-9.

48 Rubinsztein DC, Amos W, Leggo J, et al. Mutational bias provides a model for the evolution of Huntington's disease and predicts a general increase in disease prevalence. Nature Genet 1994;7:525-30.

49 Sorensen SA, Fenger K. Causes of death in patients with Huntington's disease and in affected first degree relatives. Huntington's disease and in affect

50 Pridmore S. Reproduction and the Huntington's disease process. Psychiatr Genet 1993;4:215-22. 